\title{
Thermal-Hydraulics Modeling for Prototype Testing of the W7-X High Heat Flux Scraper Element
}

\author{
Emily Clark, ${ }^{*, a}$ Arnold Lumsdaine, ${ }^{\mathrm{b}}$ Jean Boscary, ${ }^{\mathrm{c}}$ Henri Greuner, ${ }^{\mathrm{c}}$ Kivanc Ekici ${ }^{\mathrm{a}}$ \\ ${ }^{a}$ University of Tennessee, Knoxville, TN 37996, ebuckman@vols.utk.edu \\ ${ }^{b}$ Oak Ridge National Laboratory, PO Box 2008, Oak Ridge, TN 37831-6196 \\ ${ }^{c}$ Max Planck Institute for Plasma Physics, Boltzmann Str. 2, D-85748, Garching, Germany
}

\begin{abstract}
Long-pulse operation of the Wendelstein 7-X (W7-X) stellarator experiment is scheduled to begin in 2020. During this operational phase the vessel will be equipped with water-cooled plasma facing components to allow for longer pulse durations. Certain simulated plasma scenarios have been shown to produce heat fluxes that could surpass the technological limits of the divertor target elements during steady-state operation. To reduce the heat load on the target elements, the addition of a "scraper element" (SE) is under investigation. The SE is composed of 24 water-cooled carbon fiber reinforced carbon composite monoblock units. Multiple full-scale prototypes have been tested in the GLADIS high heat flux test facility. Previous computational studies revealed discrepancies between the simulations and experimental measurements. In this work, single-phase thermal-hydraulics modeling was performed in ANSYS CFX to identify potential causes for such discrepancies. Possible explanations investigated were the effects of a non-uniform thermal contact resistance and a potential misalignment of the monoblock fibers. While the difference between the experimental and computational results was not resolved by a non-uniform thermal contact resistance, the computational results provided insight into the potential performance of a W7-X monoblock unit. Circumferential temperature distributions highlighted the expected boiling regions of such a unit. Furthermore, simulations revealed that modest angles of fiber misalignment in the monoblocks result in asymmetries at the unit edges and provide temperature differences similar to the experimental results.
\end{abstract}

Keywords: Plasma facing components; Monoblock; CFC; High heat flux

\section{Introduction}

The long-pulse operation of the stellarator experiment, Wendelstein 7-X (W7-X), is scheduled to begin in 2020. During this phase, W7-X will be equipped with water-cooled plasma facing components (PFCs) to allow for pulse durations up to 30 minutes [1]. While the W7-X divertor target has been qualified to withstand steady-state heat fluxes up to $10 \mathrm{MW} / \mathrm{m}^{2}$, the lower loaded end of the target elements (near the divertor pumping space) has only been qualified up to $5 \mathrm{MW} / \mathrm{m}^{2}$ [2, 3]. One of the ten discrete divertor units can be seen in Fig. 1 . Some new plasma simulations have shown that particular operational scenarios could lead to overloading in this sensitive end region $[4,5]$. In order to reduce the heat load, a so-called "scraper element" has been proposed to shield these areas from a portion of the plasma flux (as seen in Fig. 1) [6]. The investigated technology for this actively water-cooled component is the

This manuscript has been authored by UT-Battelle, LLC under Contract No. DE-AC05-000R22725 with the U.S. Department of Energy. The United States Government retains and the publisher, by accepting the article for publication, acknowledges that the United States Government retains a non-exclusive, paid-up, irrevocable, worldwide license to publish or reproduce the published form of this manuscript, or allow others to do so, for United States Government purposes. The Department of Energy will provide public access to these results of federally sponsored research in accordance with the DOE Public Access Plan (http://energy.gov/downloads/doe-publicaccess-plan). 
carbon fiber reinforced carbon composite (CFC NB31) monoblock technology originally developed for ITER [7]. The monoblock geometry used in this study is shown in Fig. 2. Each monoblock "unit or chain” is composed of CFC monoblocks joined to a copper alloy (CuCrZr) tube by an active metal casting (AMC®) copper interlayer of $0.4 \mathrm{~mm}$. Each monoblock unit has a total length of $247 \mathrm{~mm}$, while the CuCrZr tube length is $307 \mathrm{~mm}$. The tube has an inner diameter of $12 \mathrm{~mm}$ and a thickness of $1.5 \mathrm{~mm}$, and it is equipped with a copper twisted tape insert. The twisted tape has a thickness of $1 \mathrm{~mm}$ and a twist ratio of 2, where the twist ratio characterizes the severity of the pitch as the length to diameter ratio for one $180^{\circ}$ twist. Further specifications for the monoblock geometry can be found in Ref. [8,9]. Previous studies have been performed to determine the optimum flow configuration for the scraper elements [10]. Each element consists of 24 monoblock units, where there is parallel flow into six different modules composed of four units each.

Multiple full-scale prototypes have been created consisting of four individual monoblock units. The monoblock units have been tested in the Garching Large Divertor Sample (GLADIS) high heat flux test facility at the Max Planck Institute for Plasma Physics in Garching, Germany $[8,11]$. The thermal-hydraulic performance of the prototypes was computationally investigated with a single-phase study using the ANSYS CFX commercial software. Direct comparisons to the experiments revealed differences between the simulations and measurements [8]. Possible explanations for this discrepancy could result from the manufacturing process of the monoblock prototypes. One uncertainty lies in the circumferential casting process, which could result in a better thermal contact at the top and bottom compared to the sides of the tube. Another possible explanation for the discrepancy could be a slight misalignment of CFC fibers from the normal direction. The orthotropic CFC properties are dependent upon the direction of the fibers, where the direction of maximum thermal conductivity is typically aligned parallel with the direction of the applied heat flux (the normal direction in this case) [12-14]. A slight misalignment of the fibers during the manufacturing process would result in an offset of the thermal properties. Thus, the direction of maximum thermal conductivity would correspond to a direction slightly off from the normal direction. In this work, single-phase computational modeling was performed to investigate the effects of various manufacturing results for the CFC monoblock prototypes. Parametric studies were performed to investigate the effects of a non-uniform thermal contact resistance (TCR) and misaligned CFC fibers in the monoblocks.

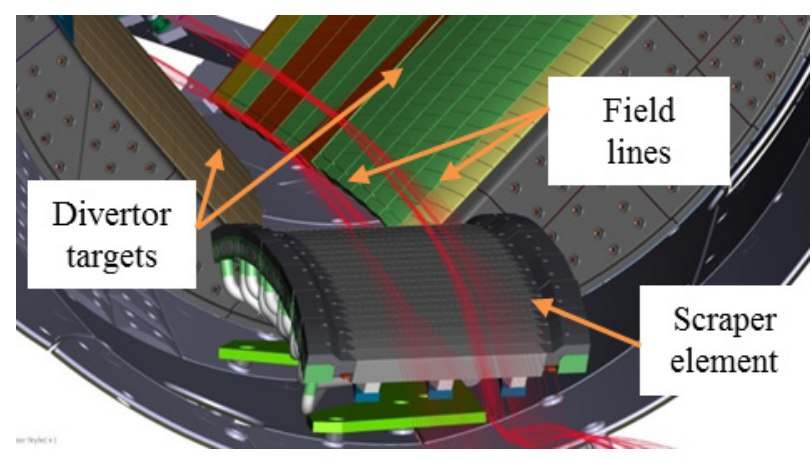

Fig. 1. W7-X divertor region (with SE) [9] 
(a)

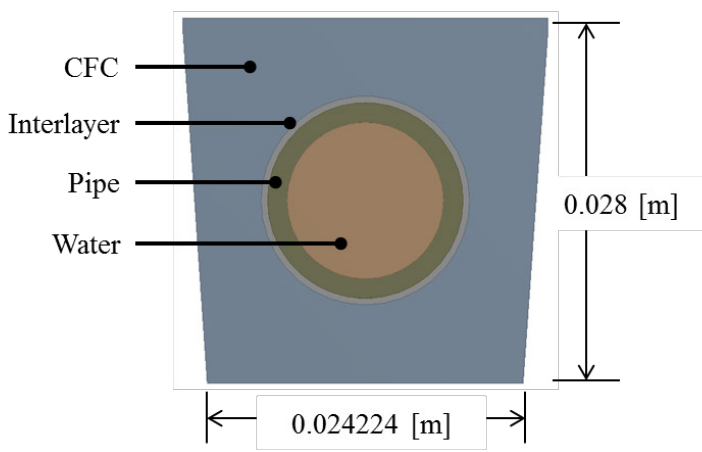

(b)

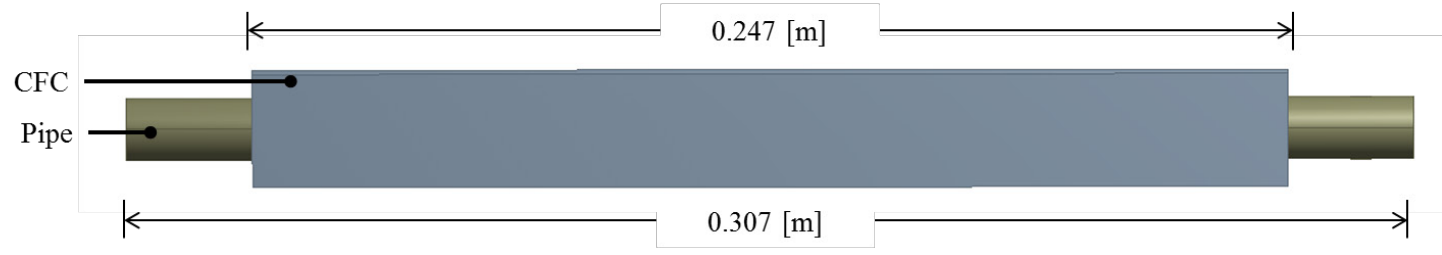

Fig. 2. (a) Axial and (b) side views of the CFC monoblock geometry implemented in CFX

\section{Thermal-Hydraulics Modeling}

Single-phase thermal-hydraulics modeling was performed using ANSYS CFX for a single monoblock finger as seen in Fig. 3. The modeling conditions were selected to match the conditions of the experimental tests performed in GLADIS [8].

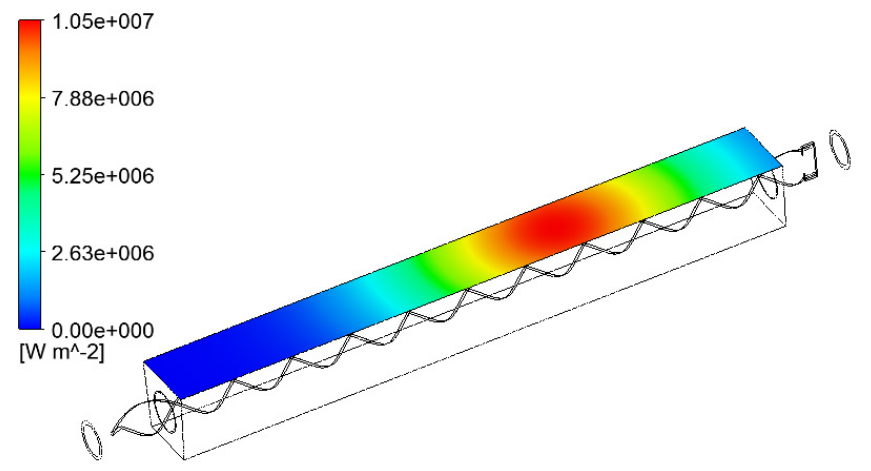

Fig. 3. Gaussian heat flux profile applied to monoblock finger

\subsection{Model Setup}

A uniform axial velocity of the water in the $\mathrm{CuCrZr}$ coolant tube with the twisted tape was specified as $12 \mathrm{~m} / \mathrm{s}$. The inlet temperature and exit pressure were set to $20^{\circ} \mathrm{C}$ and $1 \mathrm{MPa}$, respectively. A Gaussian heat flux profile was applied with three peak heat fluxes of 10.5, 15, 
and $20 \mathrm{MW} / \mathrm{m}^{2}$, where the surface heat flux distribution of the $10.5 \mathrm{MW} / \mathrm{m}^{2}$ case is shown in Fig. 3. Conjugate heat transfer was modeled from the CFC through the solid layers (including the AMC ${ }^{\circledR}$ copper interlayer and $\mathrm{CuCrZr}$ tube) and into the water. Furthermore, heat transfer was modeled throughout the solids and the water as well as at the water-tape interfaces. While there was no gap modeled between the tape and the tube, the tape-tube interfaces were considered to be adiabatic to remove any fin effect associated with the twisted tape. Radiation effects were not considered in this work. The water was modeled with temperature and pressure dependent properties according to the International Association for the Properties of Water and Steam (IAPWS) [15, 16]. Orthotropic and temperature dependent thermal conductivity values were implemented for the CFC according to the equations given in Ref. [12-14]. Figure 4 shows the temperature dependent properties used for the CFC thermal conductivity. The other solids, including the AMC ${ }^{\circledR}$ copper interlayer, CuCrZr tube, and twisted tape, were modeled with constant properties as shown in Table 1. While the prototype was equipped with a copper twisted tape, the simulations were performed with a stainless steel (SS316) tape. This difference is noted for disclosure. However, due to the insulation of the tape from the tube, the tape material will have a negligible effect on the thermal performance of the device.

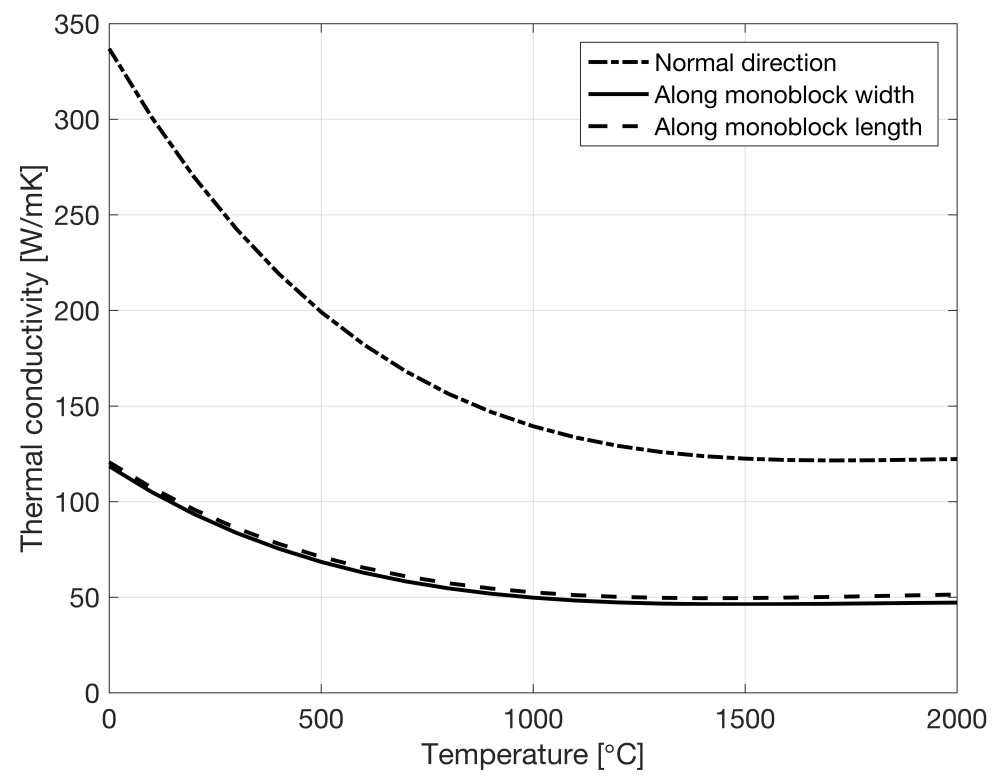

Fig. 4. Temperature dependent thermal conductivity of CFC NB31

Table 1: Material properties of solid components in computational model

\begin{tabular}{|c|c|c|c|}
\hline Material & $\begin{array}{c}\text { Density } \\
{\left[\mathrm{kg} / \mathrm{m}^{3}\right]}\end{array}$ & $\begin{array}{c}\text { Specific Heat Capacity } \\
{[\mathrm{J} / \mathrm{kgK}]}\end{array}$ & $\begin{array}{c}\text { Thermal Conductivity } \\
{[\mathrm{W} / \mathrm{mK}]}\end{array}$ \\
\hline AMC@ Copper & 8933 & 385.0 & 150.0 \\
\hline CuCrZr & 8900 & 389.9 & 325.6 \\
\hline SS316 & 8031 & 464.7 & 13.6 \\
\hline CFC NB31 & 1959 & 1030.9 & See Fig. 3 \\
\hline
\end{tabular}


The simulations were performed using the shear stress transport (SST) turbulence model, which is recommended by ANSYS for high accuracy boundary layer simulations [17]. The use of the SST model requires a refined mesh, with a non-dimensional wall coordinate of $\mathrm{y}^{+}<1$. A mesh study was performed for the highest peak heat flux. The mesh was refined successively until the maximum CFC temperature and the pressure drop changed less than $1 \%$ from case to case. The meshing criterion was chosen such that a volume averaged non-dimensional wall coordinate of $\mathrm{y}^{+}<1$ was generated. The mesh refinement was only performed for the highest peak heat flux because this case would result in the most extreme temperatures. Lower temperatures would be expected for lower peak heat fluxes, which would lead to reduced non-dimensional wall coordinate values. Thus, the same mesh was used for all peak heat fluxes investigated. The final mesh is shown in Fig. 5. Inflation layers were implemented on the water-solid interface (including the tape), and the final mesh had roughly 9 million elements.

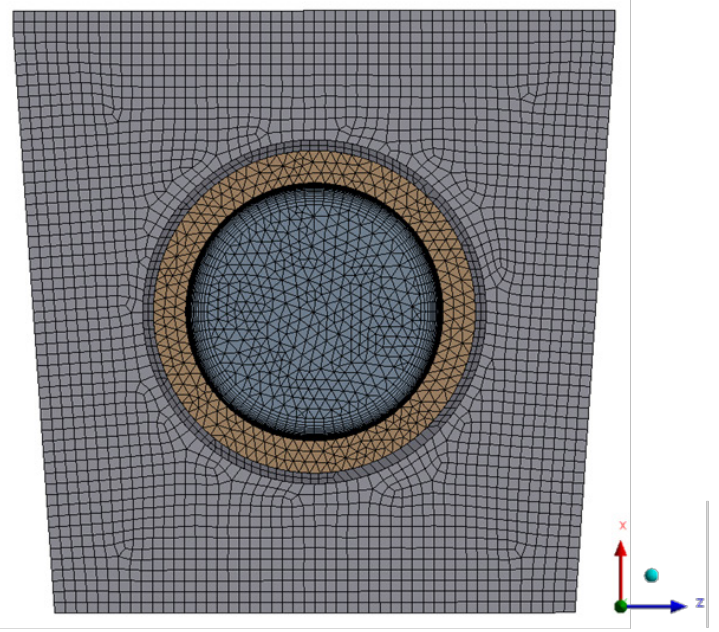

(a)

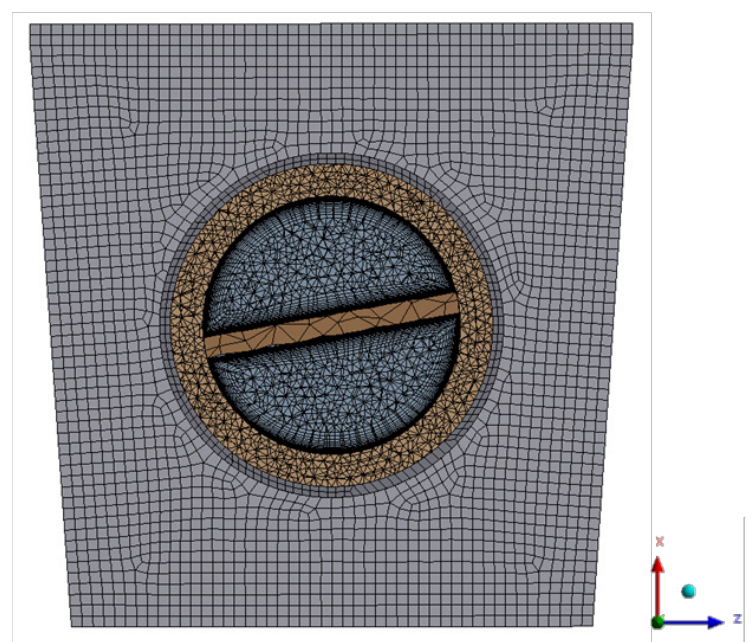

(b)

Fig. 5. Axial view of the final mesh (a) from the end point and (b) at a split plane

\subsection{Modeling Method for Non-uniform Thermal Contact Resistance}

Two parametric studies were performed to investigate the effect of a non-uniform TCR between the CFC and copper interlayer which would result, in part, from the difficulty in integrating the CFC PAN fibers with a curved tube. The first was a "baseline" case, which included a constant TCR. A circumferentially varying TCR was developed for the second set of simulations to mimic the possible variation that could occur during the circumferential bonding process. Equation (1) was created for the contact conductance (CC) on the CFC-interlayer interface such that the conductance varies from $1 \times 10^{4}$ to $1.5 \times 10^{6} \mathrm{~W} / \mathrm{m}^{2} \mathrm{~K}$ from the sides to the top of the tube, respectively. These conductance values were based on a thermal circuit analysis, where the TCR would result in a reduced "equivalent" thermal conductivity in the AMC ${ }^{\circledR}$ copper interlayer. In this analysis, the interlayer "equivalent" thermal conductivity was chosen to vary from 5 to $125 \mathrm{~W} / \mathrm{mK}$. This thermal conductivity range was used to determine the corresponding TCR values, and the CC range was calculated as the inverse of the TCR. 


$$
C C=7.45 \times 10^{5} \cos (2 \theta-\pi)+7.55 \times 10^{5}\left[\mathrm{~W} / \mathrm{m}^{2} \mathrm{~K}\right]
$$

In Equation (1), $\theta$ is the circumferential angle (as shown in Fig. 6). The TCR is entered into ANSYS CFX as the inverse of the CC. The applied TCR is shown in Fig. 7, where the TCR is higher at the sides compared to the rest of the tube.

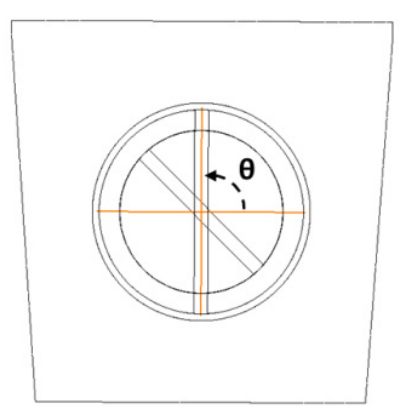

Fig. 6. Circumferential angle $(\theta)$ on the monoblock geometry

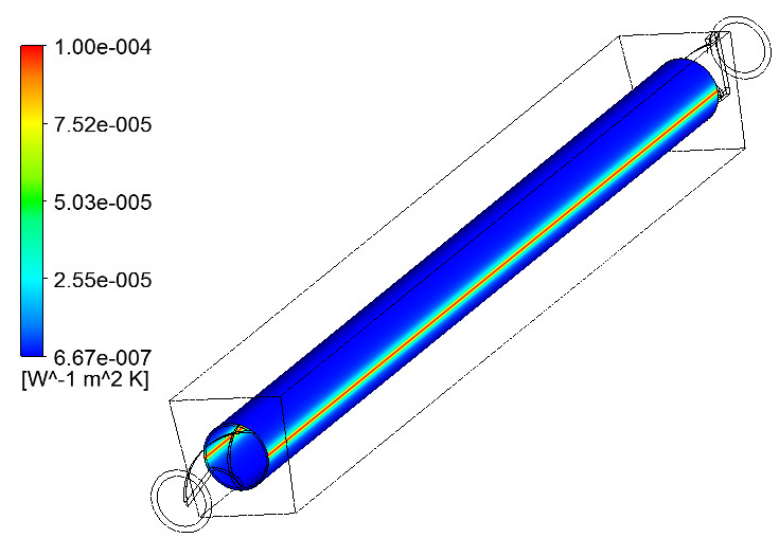

Fig. 7. Non-uniform TCR on CFC-Interlayer interface

\subsection{Modeling Method for Misaligned CFC Fibers}

As discussed in Section 2.1, the CFC thermal conductivity was modeled as orthotropic and temperature dependent according to Ref. [12-14]. In order to simulate a misalignment of CFC fibers, the thermal properties were defined based on a rotated coordinate frame in CFX (as seen in Fig. 8). The investigation was performed for a peak heat flux of $10.5 \mathrm{MW} / \mathrm{m}^{2}$ and a nonuniform thermal contact resistance (as shown in Fig. 7). The coordinate frame for the CFC thermal properties was rotated by three angles $(\phi)$ of $1.7,3,8.5^{\circ}$. 


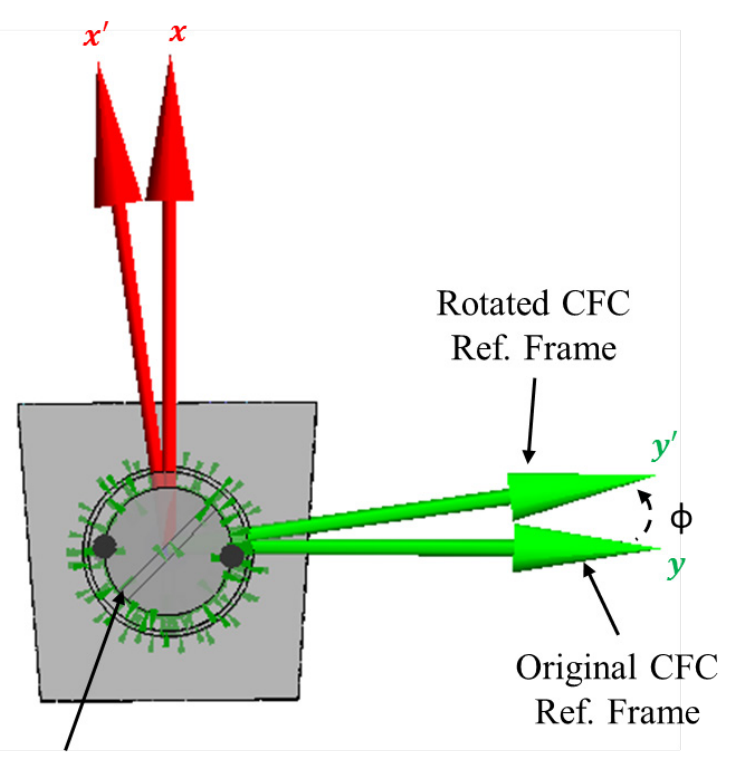

Inlet

Fig. 8. Rotated coordinate frame for misaligned CFC thermal properties

\subsection{Post-processing Method}

The experimental data were taken from infrared images at the CFC surface at the location of peak heat flux as seen in Ref. [8]. In order to compare the simulated results to the experiments, three points were created at the same location along the CFC surface as shown in Fig. 9. The peak temperature values were pulled from these positions.

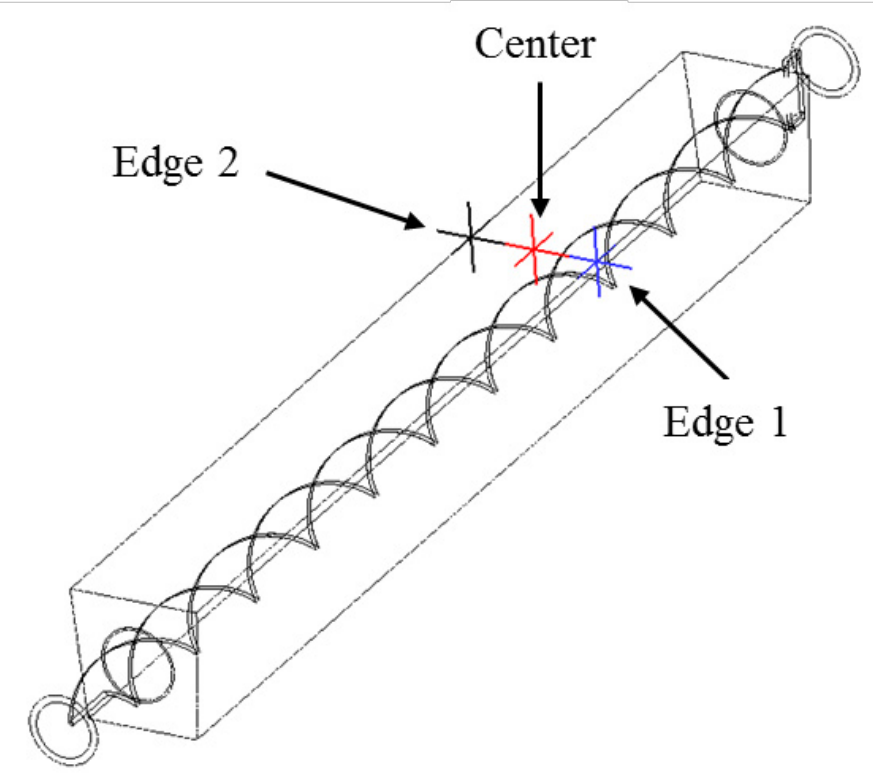

Fig. 9. Points for post-processing computational results 


\section{Results}

\subsection{Non-uniform Thermal Contact Resistance Results}

The computational results were compared to the experimental results from the GLADIS testing as seen in Ref. [8]. Note that the accuracy and reproducibility of the loading parameter in GLADIS is $\pm 5 \%$. Figures 10 and 11 show the comparisons at the center and edges of the monoblock, respectively. The experimental data revealed a discrepancy between the temperature at the two edges, and thus, Ref. [8] provides results for both edge locations. However, there was no such discrepancy noted in the simulation results. The computational values in Fig. 11 represent the data taken at Edge 1 (as seen in Fig. 9). The computational results from Ref. [8] are re-plotted in Figures 10 and 11. In the previous study [8], no additional TCR was added to the model, and thus, these results are indicated by "No TCR" in the legend of Figures 10 and 11 . In all cases, the computational results underpredict the experimentally measured temperature at the center of the monoblock finger, while the edge temperatures are at the bottom range of the experimental values. Modeling a constant or non-uniform TCR reveals a minimal difference at the center and only a slight difference at the edges of the monoblock finger. Another possible explanation for the discrepancy between the experiments and simulations is the strong influence of variations in the local thermal properties of the CFC. There are many factors leading to material property variations in CFC such as manufacturing inconsistencies in the fiber bundles or weaves.

The circumferential temperature distribution, as seen in Fig. 12, highlights the difference between a uniform and non-uniform TCR. The distribution was created by extracting the results along a circle at the water-tube interface under the peak heat flux location. The gaps in the plot represent the locations where the twisted tape connects to the tube wall. The results are plotted along with the saturation temperature (Tsat) at $1 \mathrm{MPa}$, which is $180^{\circ} \mathrm{C}$. As expected, the locations with the largest difference occur at the sides of the tube, where the imposed TCR was higher $\left(\theta=0^{\circ}, 180^{\circ}\right.$ as seen in Fig. 6 and 7$)$. The temperature distribution reveals that only the case with a peak heat flux of $10.5 \mathrm{MW} / \mathrm{m}^{2}$ remains below saturation everywhere. Subcooled nucleate boiling would be expected at the top of the tube for the higher peak heat fluxes. The nucleate boiling would result in further discrepancies between the experimental data and computational solution. Further discrepancies would be indicated because the increased heat transfer due to the boiling process would lead to decreased surface temperatures. The current computational model is single-phase and does not capture the boiling process. Thus, this results in inflated surface temperatures at higher heat fluxes. 


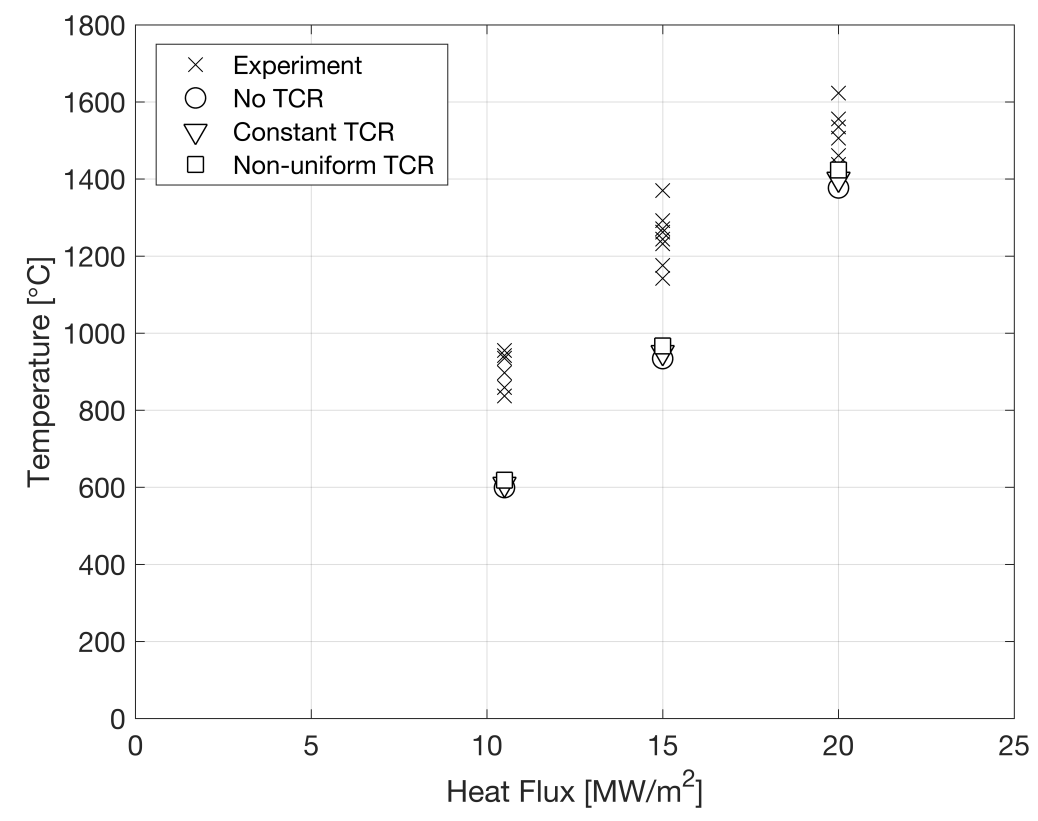

Fig. 10. Comparison of experimental values [8], previous CFX results [8], and CFX results for the current study at the center of the monoblock

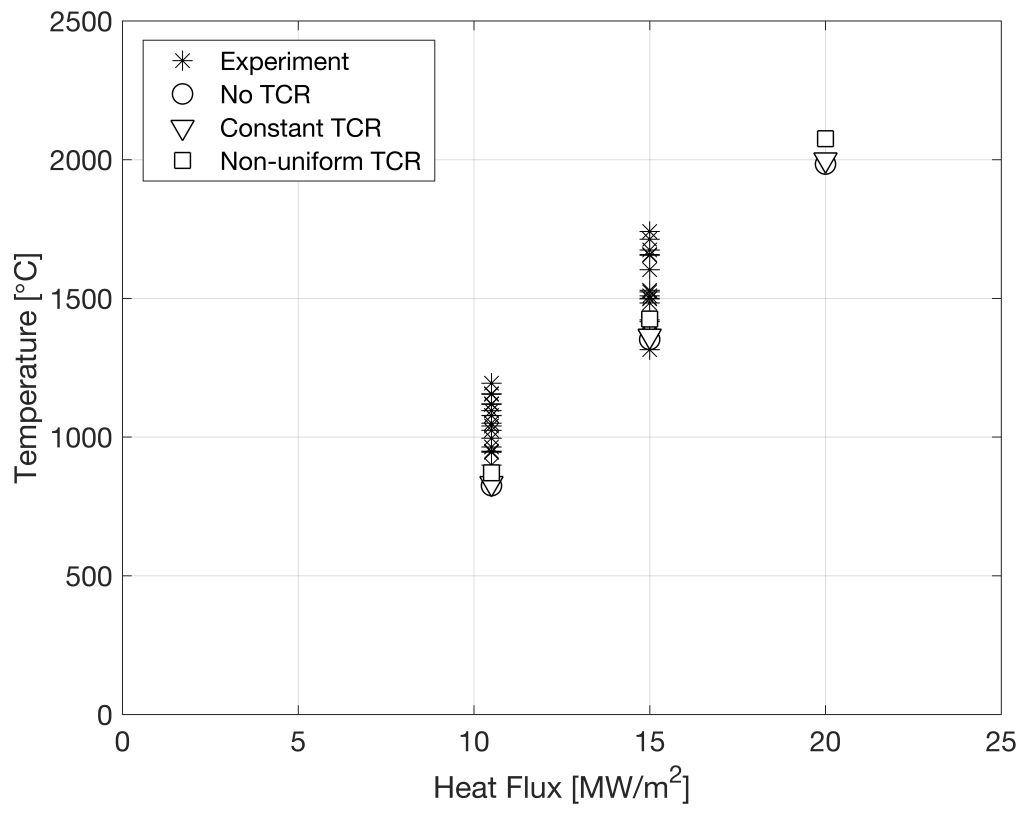

Fig. 11. Comparison of experimental values [8], previous CFX results [8], and CFX results for the current study at the edges of the monoblock 


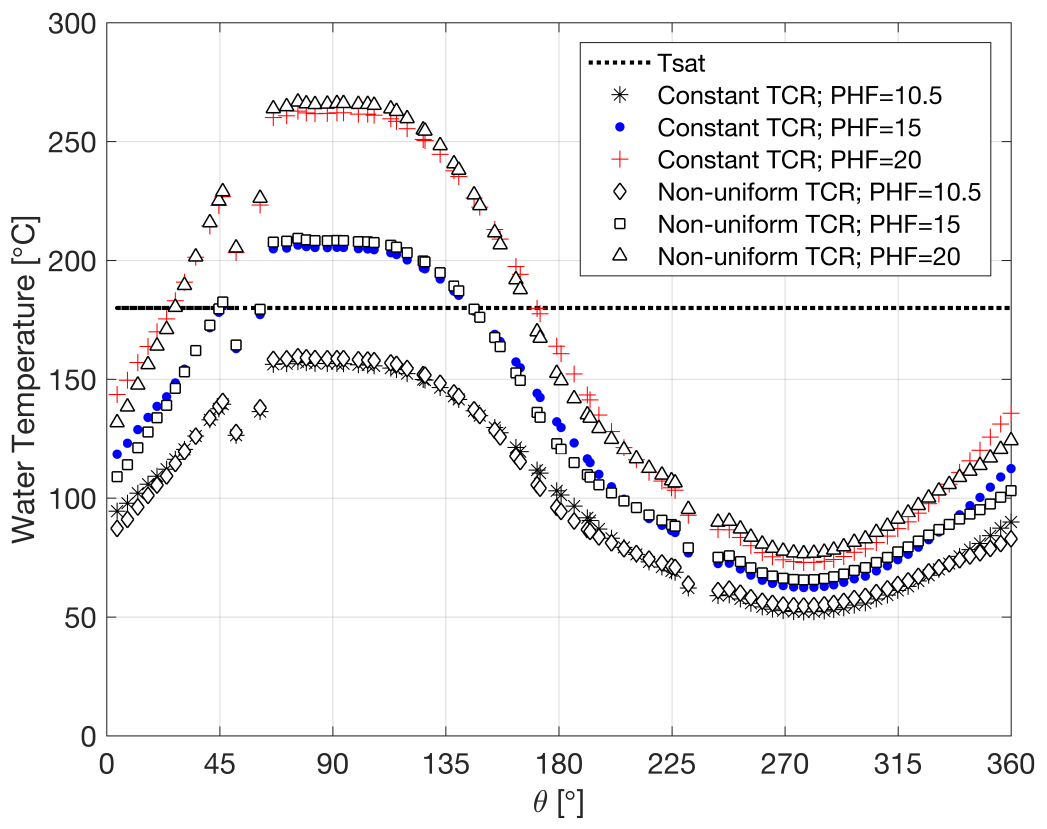

Fig. 12. Circumferential temperature distribution at location of peak heat flux

\subsection{Misaligned CFC Fibers Results}

As mentioned in Section 3.1, the experimental data revealed a noticeable difference between the temperature at the two edges [8]. This temperature difference $\left(\Delta \mathrm{T}_{\text {edges }}\right)$ was not observed in the computational results. One possible explanation behind the temperature difference at the edges could be the impact of misaligned CFC fibers. A slight misalignment of the fibers during the manufacturing process could result in misaligned orthotropic thermal properties. This potential misalignment was modeled as discussed in Section 2.3. The thermal properties were defined based on the rotated coordinate frame $\left(y^{\prime}, x^{\prime}\right)$ shown in Fig. 8. In these cases, the maximum thermal conductivity was no longer acting normal to the top of the monoblock $(-x)$, but rather $\phi^{\circ}$ off normal. The rotated CFC properties resulted in asymmetries in the surface temperature similar to those seen in the experiments. Figure 13 shows the surface temperature contour for the most extreme rotation angle investigated $\left(\phi=8.5^{\circ}\right)$. The surface temperature values at the center and edge points can be found in Table 2. A comparison between the edge temperature difference ( $\left.\Delta \mathrm{T}_{\text {edges }}\right)$ from the experiments [8] and the simulations is shown in Fig. 14. In the experimental setting, the average $\Delta \mathrm{T}_{\text {edges }}$ for a peak heat flux of $10.5 \mathrm{MW} / \mathrm{m}^{2}$ was about $112^{\circ} \mathrm{C}$. The $\Delta \mathrm{T}_{\text {edges }}$ noted in the simulations is plotted directly against this average value from the experiments. Figure 14 shows that a rotation of $\phi=3^{\circ}$ gives an edge temperature difference similar to the average value seen in the experiments. These results reveal that even modest angles of misalignment can result in asymmetries at the outer monoblock edges. 


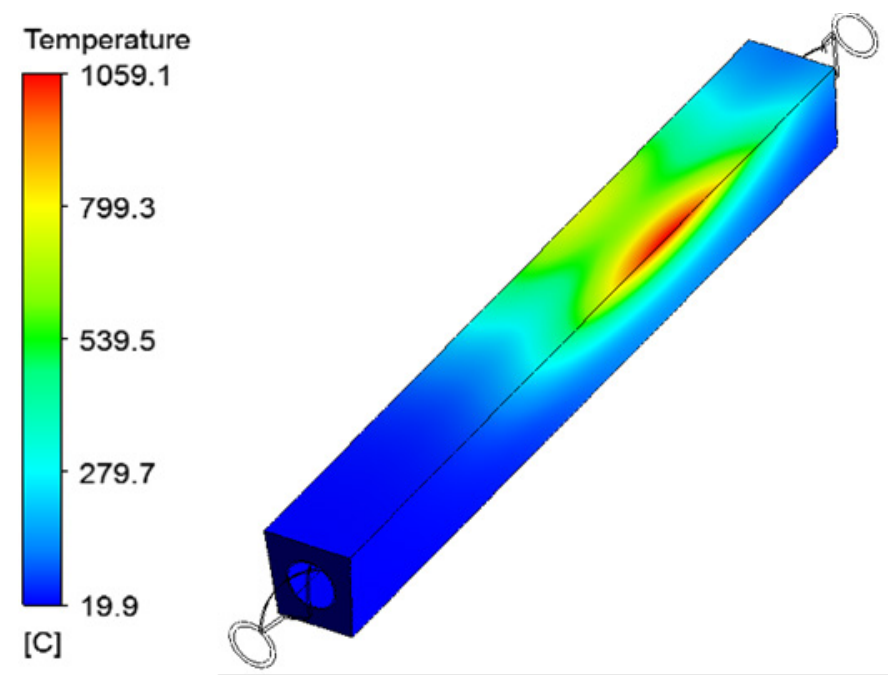

Fig. 13. Temperature contour for rotated CFC $\left(\phi=8.5^{\circ}\right)$ with a peak heat flux of $10.5 \mathrm{MW} / \mathrm{m}^{2}$

Table 2. Surface temperature values at the center and edge points for rotated CFC with a peak heat flux of $10.5 \mathrm{MW} / \mathrm{m}^{2}$

\begin{tabular}{|c|c|c|c|}
\hline$\phi\left[{ }^{\circ}\right]$ & Center Temp. $\left[{ }^{\circ} \mathrm{C}\right]$ & Edge Pt. 1 Temp. $\left[{ }^{\circ} \mathrm{C}\right]$ & Edge Pt. 2 Temp. $\left[{ }^{\circ} \mathrm{C}\right]$ \\
\hline 0 & 618.4 & 870.9 & 879.6 \\
\hline 1.7 & 618.5 & 904.0 & 847.2 \\
\hline 3 & 619.2 & 929.8 & 825.1 \\
\hline 8.5 & 628.8 & 1059.0 & 742.0 \\
\hline
\end{tabular}

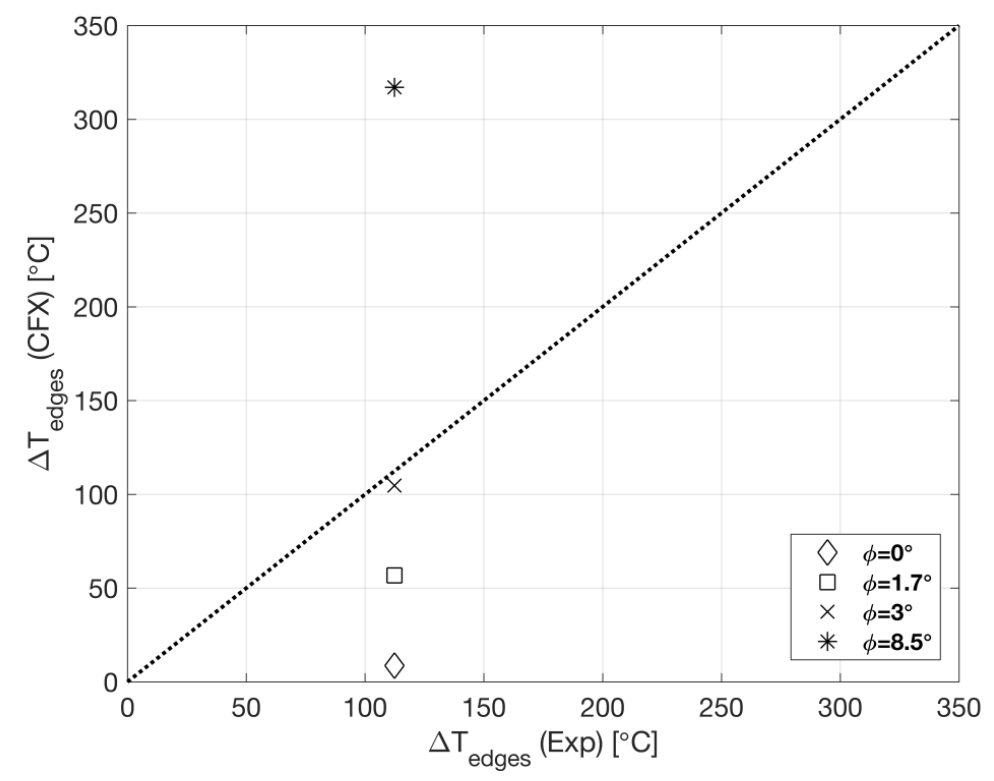

Fig. 14. Comparison of edge temperature differences ( $\left.\Delta \mathrm{T}_{\text {edges }}\right)$ between simulated and experimental [8] results as various rotation angles 


\section{Conclusions}

Thermal-hydraulics modeling was performed in ANSYS CFX to support the monoblock prototype testing for the W7-X divertor scraper element. Previous studies revealed discrepancies in the range of approximately $>10 \%$ between the computationally predicted and the measured surface temperatures in the GLADIS testing. However, the measured surface temperatures did not increase during the performed cyclic heat leading as would be expected for growing defects of the component. Potential explanations for those discrepancies were found in the monoblock manufacturing process including a non-uniform thermal contact resistance between the CFC and interlayer and a potential misalignment of CFC fibers. Both were investigated in this work. The difference between the experimental and computational results was not resolved by the addition of a non-uniform TCR, which did not yield significant changes to the simulated results. However, circumferential temperature distributions provided insight into the expected boiling characteristics in the W7-X monoblock finger. The circumferential temperature distribution revealed that only the case with a peak heat flux of $10.5 \mathrm{MW} / \mathrm{m}^{2}$ remained below saturation everywhere. Subcooled nucleate boiling occurs at the top of the tube under higher peak heat fluxes. At these locations, the boiling process will increase the heat transfer from the surface to the water and result in overall lower surface temperatures. This phenomenon cannot be captured with a single-phase model, which leads to further differences between the experimental data and computational simulations at those higher heat fluxes. The misalignment of CFC fibers could be a potential answer to the discrepancy between the experimental and computational results. The CFC thermal properties were rotated by three angles for a peak heat flux of $10.5 \mathrm{MW} / \mathrm{m}^{2}$. The simulations revealed that even modest angles of misalignment result in asymmetries at the edges of the monoblocks. A rotation angle of $3^{\circ}$ resulted in calculated edge temperature differences ( $\left.\Delta \mathrm{T}_{\text {edges }}\right)$ that were similar to those observed in the experimental work. While this work incorporated a temperature dependent CFC thermal conductivity, it did not address a potential degradation of the CFC properties due to high heat loads. Future work could include an investigation into this effect of lower CFC thermal conductivities due to degradation in the material.

\section{Acknowledgements}

This material is based upon work supported by the U.S. Department of Energy, Office of Science, Office of Fusion Energy Science under contract number DE-AC05-000R22725. This work was partially supported by the Federal Ministry of Education and Research of the Federal Republic of Germany under Grant 03FUS0014A. 


\section{References}

1. H.-S. BOSCH et al., "Technical challenges in the construction of the steady-state stellarator Wendelstein 7-X,” Nucl. Fusion, 53(12), 126001 (2013).

2. H. GREUNER et al., "Performance and statistical quality assessment of CFC tile bonding on the pre-series elements of the Wendelstein 7-X divertor," Fusion Eng. and Des., 86, 16851688 (2011).

3. J. BOSCARY et al., "Design improvement of the target elements of Wendelstein 7-X divertor,” Fusion Eng. and Des., 87, 1453-1456 (2012).

4. J. LORE et al., "Design and Analysis of Divertor Scraper Element for the W7-X Stellarator," IEEE Trans. on Plasma Sci., 42, 539-544 (2014).

5. J. LORE et al., "Heat Flux and Design Calculations for the W7-X Divertor Scraper Element," Proc. of the $24^{\text {th }}$ IAEA Fusion Energy Conf., San Diego, CA (2012).

6. A. LUMSDAINE et al., "Modeling and analysis of the W7-X divertor scraper element," IEEE Trans. on Plasma Sci., 42, 545-551 (2014).

7. A. CARDELLA et al., "Design, manufacturing and thermo-mechanical testing of a relevant size monoblock divertor prototype,” Fusion Technol., 282-286 (1994).

8. J. BOSCARY, et al., "Prototyping phase of the high heat flux scraper element of Wendelstein 7-X,” Fus Eng. and Des., 109-111, 773-776 (2016).

9. E. CLARK et al., "Multiphysics analysis of the W7-X actively cooled scraper element," Fusion Sci. Technol., 68, 635-639 (2015).

10. A. LUMSDAINE et al., "Design and analysis of the W7-X divertor scraper element," Fusion Eng. and Des., 88, 1773-1777 (2013).

11. H. GREUNER et al., "Design, performance and construction of a $2 \mathrm{MW}$ ion beam test facility for plasma facing components,” Fusion Eng. and Des., 75, 345-350 (2005).

12. V. BARABASH and C. H. WU, ITER Material Properties Handbook, ITER_D_G74MA9 (2000).

13. J. P. BONAL, D. MOULINIER, “Thermal properties of advanced carbon fiber composites for fusion application,” No. DMT-95-495, (1995).

14. J. P. BONAL, "Thermal properties of carbon fiber composites before irradiation in Paride 3/4 experiment,” No. DMT SEMI-LM2E-RT2004.

15. W. WAGNER et al., "The IAPWS Industrial Formulation 1997 for the Thermodynamic Properties of Water and Steam,” J. Eng. Gas Turbines Power, 122(1), 150-184 (2000).

16. W. WAGNER and H. J. KRETZSCHMAR, International Steam Tables: Properties of Water and Steam Based on the Industrial Formulation IAPWS-IF97, second ed., Springer, Germany, 2008.

17. ANSYS INC., “ANSYS CFX-Solver Modeling Guide (R16.1 ed),” (2015). 